\title{
Screening for congenital hypothyroidism in Iran.
}

\author{
Bita Najafian $^{1}$, Ehsan Shahverdi ${ }^{2,3 *}$, Sadaf Modaresi ${ }^{4}$ \\ ${ }^{1}$ Department of Pediatrics, Baqiyatallah University of Medical Sciences, Tehran, Iran \\ ${ }^{2}$ Blood Transfusion Research Center, High Institute for Research and Education in Transfusion Medicine, Tehran, Iran \\ ${ }^{3}$ Student Research Committee, Baqiyatallah University of Medical Sciences, Tehran, Iran \\ ${ }^{4}$ Department of Medicine, Najafabad Branch, Islamic Azad University, Najafabad, Iran
}

Accepted on November 23, 2016

Thyroid dysgenesis (TD) is the most frequent cause of congenital hypothyroidism $(\mathrm{CH})$ that is the most common endocrine disease occurring in about 1 of 3000 to 1 of 4000 live births [1]. The pathogenesis of thyroid dysgenesis is as yet unclear, and the disease is usually defined as sporadic with a female predominance [2]. Furthermore, some familial cases of congenital hypothyroidism caused by thyroid dysgenesis have been reported with either athyreosis [3,4] or ectopic gland [5-7].

Studies have suggested that an increased incidence of $\mathrm{CH}$ is on the rise due to possible roles of autoimmune [8,9] or environmental factors [10]. Based on epidemiological studies, there is a lower incidence of the disease in African American infants [11] and a higher prevalence of extra thyroidal congenital anomalies is reported from infants with $\mathrm{CH}$ compared with the general population [12]. These arguments are in favor of a possible genetic component.

Thyroid normal function is of necessary factors for the growth of both physical and mental health of infants and so congenital hypothyroidism can lead to preventable mental retardation [8]. Therefor thyroid screening is seems to be vital. The thyroid screening in many developed countries is routinely performed by measuring TSH (thyroid-stimulating hormone) and T4 cord blood or neonatal heel blood [13].

In 2005, national program of neonatal screening was performed in Iran. Based on national studies, the incidence of congenital hypothyroidism was reported as one in every 670 live births in 2011. The mean prevalence of the disease is estimated to be 1 in 1,000 in Iran. So in compared with the prevalence rate in the world ( 1 in 3000), this rate revealed a high prevalence rate of the disease in Iran [13].

The incidence of hypothyroidism according to our previous study is $0.4 \%$ and the prevalence of neonatal hypothyroidism was estimated to be $1 / 200$ birth. In this study that was done on 11000 infants, we found that the incidence of hypothyroidism based on either TSH or FT4 was higher in girls than in boys nonsignificantly.

In term of recall rate, according to some comprehensive studies $[8,14]$, the recall rate is between $2.6 \%$ and $3 \%$ in Iran, that demonstrate higher recall rate than many of others regions of world.

Based on some studies, babies delivered by cesarean section are significantly more likely to have neonatal hypothyroidism (TSH levels greater than $5 \mathrm{uU} / \mathrm{ml}$ ] than those delivered vaginally [8]. With the rise in the rate of births by cesarean, this could be an important factor in assessing population iodine deficiency using neonatal TSH levels. So because of high prevalence of neonatal hypothyroidism in Iran and the results of many studies, the importance of the neonatal screening program and encourage mothers to normal vaginal delivery are emphasized.

\section{References}

1. Fisher DA. Second International Conference on Neonatal Thyroid Screening: Progress report. J Pediatr. 1983;102:653-654.

2. Castanet M, Polak M, Bonaïti-Pellié C, et al. Nineteen years of national screening for congenital hypothyroidism: familial cases with thyroid dysgenesis suggest the involvement of genetic factors. J Clin Endocrinol Metab. 2001;86:2009-2014.

3. Ainger Le, Kelley Vc. Familial athyreotic cretinism: Report of 3 cases. J Clin Endocrinol Metab. 1955;15:469-475.

4. Greig W, Henderson A, Boyle J, et al. Thyroid dysgenesis in two pairs of monozygotic twins and in a mother and child. J Clin Endocrinol Metab. 1966;26:1309-1316.

5. Rollo R, Cavalieri R. Lingual thyroid in two members of a family. West J Med. 1977;126:400.

6. Kaplan M, Kauli R, Raviv U, et al. Hypothyroidism due to ectopy in siblings. Am J Dis Child. 1977;131:1264-1265.

7. Rosenberg T, Gilboa Y. Familial thyroid ectopy and hemiagenesis. Arch Dis Child. 1980;55:639-641.

8. Najafian B, Shahverdi E, Afsharpaiman S, et al. Neonatal screening for congenital hypothyroidism in an University Hospital in Tehran, Iran. Journal of Comprehensive Pediatrics. 2016

9. Van der Gaag R, Drexhage H, Dussault J. Role of maternal immunoglobulins blocking TSH- induced thyroid growth in sporadic forms of congenital hypothyroidism. Lancet. 1985;325:246-250.

10. Reijneveld SA, Verkerk PH. No evidence for seasonality of congenital hypothyroidism in The Netherlands. Scandinavian University Press PO Box 2959 Toyen. Journal division customer service, N-0608 Oslo, Norway. 1993;80:212-213.

11. Grant D, Smith I. Survey of neonatal screening for primary hypothyroidism in England, Wales and Northern Ireland 1982-4. Br Med J (Clin Res Ed). 1988;296:1355-1358.

12. Devos H, Rodd C, Gagné N, et al. A search for the possible molecular mechanisms of thyroid dysgenesis: Sex ratios and associated malformations. J Clin Endocrinol Metab. 1999;84:2502-2506. 
13. Eftekhari N, Asadikaram GR, Khaksari M, et al. The prevalence rate of congenital hypothyroidism in Kerman. Iran in 2005-2007. Journal of Kerman University of Medical Sciences. 2008;15:243-250.
14. Hashemipour M, Amini M, Kelishadi R, et al. Seasonal variation in the incidence of congenital hypothyroidism in Isfahan, Iran. Saudi Med J. 2007;28:1582-1586.

\section{*Correspondence to:}

Ehsan Shahverdi

Iranian Blood Transfusion Organization Building Hemmat Exp. Way

Tehran

Iran

Tel: +982188601606

E-mail: shahverdi_ehsan@yahoo.com 